\title{
Electronic Structure, Nonlinear Optical Properties and Spectroscopic Studies of 4-Methyl-3-Nitropyridine-1- Carbonitrile using Density Functional Theory
}

\author{
I. Ragavan' ${ }^{1}$ A. Prakasam ${ }^{2}$ and P.M. Anbarasan ${ }^{*}$
}

${ }^{1}$ Department of Physics, Periyar University, Salem 636 011, Tamilnadu, India

${ }^{2}$ Department of Physics, Thiruvalluvar Goverment Arts College, Rasipuram 637401, Tamilnadu, India

\begin{abstract}
The structural, electronic, and spectroscopic properties of 4-Methyl-3-nitropyridine-1-carbonitrile (4MNC) have been investigated from theoretical and vibrational spectroscopic point of view employing quantum chemical method utilizing GAUSSIAN 09. A detailed study of geometrical parameters, Infrared and Raman spectra, and electronic properties were performed by density functional theory (DFT) at Becke-3-Lee-Yang-Parr (B3LYP) and HF Methods by employing 6$311++G(d, p)$ basis sets. The FTIR and FT-Raman Spectra has been recorded using Fourier transform FT-IR and FT-Raman spectroscopy in the region 4000-400 $\mathrm{cm}^{-1}$.The energy gap between Highest Occupied Molecular Orbital (HOMO) - Lowest Unoccupied Molecular Orbital (LUMO) is measured. The HOMO and LUMO study suggests the existence of charge transfer within the molecule. The NLO properties such as polarizability $\left(\alpha_{\text {tot }}\right)$ and molecular first order hyperpolarizability $(\beta)$ and thermodynamic analysis of the title compound are computed with DFT/B3LYP and HF 6-311++G (d,p) level of theory. These results indicate that 4-Methyl-3-nitropyridine-1-carbonitrile could be candidate compounds for the potential use in application such as solar cells and biochemistry.
\end{abstract}

KEYWORDS: DFT, electronic properties, NLO and spectroscopic properties (FTIR and FT-Raman), Thermal properties.

(C) 2017 mahendrapublications.com, All rights reserved

\section{INTRODUCTION}

The pyridine and their derivatives are widely used as starting materials in a vast amount of chemicals, pharmaceuticals, dyes, electro optical and many other industrial processes [1].In drug discovery, it was well demonstrated that to avoid screening millions of compounds, one might attempt to bias combinatorial chemistry efforts to produce a set of molecules, which contain drug like patterns such as the pyridine heterocyclic ring [2] From the perspective of structural diversification, we were interested in pyridine scaffolds bearing reactive orthogonal functional groups, with minimal protecting group transformation and synthetic manipulations. The study of the vibrational spectra of substituted pyridine mainly amino pyridine attracts the attention of many spectroscopists due to their wide application in pharmacology and agro-chemistry. Pyridine heterocycles are a repeated moiety in many large molecules with interesting photo physical, electrochemical and catalytic applications [3-10]. Most recently, Guoqiang Wang et al. [11] reported a metal-free approach to the synthesis of C-4 substituted pyridine derivatives was predicted computationally and verified experimentally. Theoretical calculations revealed that the in situ generated pyridineboryl radical using 4-cyanopyridine and $\mathrm{B}_{2}$ (pin) 2 exhibits a carbon-radical characteristic, and this boryl radical can be used as a bifunctional "reagent", which acts as not only a pyridine precursor but also a boryl radical .Kandasamy et al. [12], the FTIR and FT-Raman spectra of 3-and 4- amino2-bromopyridine have been reported together with the vibrational assignments of the vibrational modes. Sundaraganesan et al. [13-15] reported the FTIR and FTRaman spectra of 2-amino-5-chloropyridine, 2amino5iodopyridine and 4-N, N-dimethylamino pyridine by using HF and DFT calculations. Sundaraganesan et al. [16] studied the molecular structure and vibrational spectra of 2- amino-5-methyl pyridine and 2-amino-6-methyl pyridine by density functional methods.

To the best of our knowledge, no theoretical work about the vibrational frequency, NLO properties, thermodynamic analysis and frontier molecular orbital has been reported for the title compound until now.

Considering the pharmacological and biochemical importance of the title compound 4-Methyl-3nitropyridine-1-carbonitrile (4MNC) led to the complete FT-IR and FT-Raman vibrational studies on the fundamental modes and frontier molecular orbitals (FMO's) and thermodynamic analysis using DFT and HF methods by employing $6-311++G(d, p)$ basis sets. The optimized geometry, FMO's and their energy gaps and molecular electrostatic potential (MESP) map have been constructed at B3LYP/6-311++G (d, p) level to understand the electronic properties, electrophilic and nucleophilic active centers of title compound.

\section{COMPUTATIONAL DETAILS}

The density functional theory (DFT) were used to carry out the optimization of the geometry and to determine vibrational wavenumbers of $4 \mathrm{MNC}$, with the 2009 version of the Gaussian suite [17] using DFT/B3LYP and HF the methods [18,19] supplemented with standard 6$311++G(d, p)$ basis sets. The vibrational modes were assigned by means of visual inspection using GAUSSVIEW program [20]. The vibrational mode analysis of $4 \mathrm{MNC}$ is presented in some detail in order to better describe the basis for the assignments, from the basic theory of Raman scattering. In this investigation we observed that the calculated frequencies were slightly greater than the fundamental frequencies. To improve the agreement between the predicted and observed frequencies, the computed harmonic frequencies are usually scaled for

\section{*Corresponding Author: anbarasanpm@gmail.com}


comparison. In this work the force field was scaled according to the SQM procedure [21] and the Cartesian representation of the force constants were transferred to a non-redundant set of local symmetry coordinates, chosen in accordance to the recommendations of Pulay et al. [22]. Calculation of the potential energy distribution (PED) and the prediction of IR intensities and Raman activities were done on a PC with the MOLVIB Program (Version V7) written by Sundius [23].

\section{RESULT AND DISCUSSION}

\subsection{Molecular geometry}

The molecule $4 \mathrm{MNC}$ has 17 atoms with 45 normal modes of vibration. It belongs to the $\mathrm{C} 1$ point group symmetry. Fig. 1 (a) shows the optimized geometry of the compound and Table 1 presents the optimized values obtained for bond lengths and bond angles. The various bond lengths and bond angles are found to be almost same at HF and B3LYP methods. The bond lengths between $\mathrm{C} 1-\mathrm{C} 2$ in $\mathrm{HF}$ and B3LYP method are found to be 1.2827 and 1.2981 respectively (Fig.1(b)). The bond length between C1-N6 in HF and B3LYP are 1.3181 and 1.3381 respectively.

The bond angle between N16-C12-C17 in HF and B3LYP are 108.95 and 124.02 respectively (Fig. 1 (c)). The bond angle between C2-C1-6N in HF and B3LYP are 124.26 and 111.1. The HF value is in good agreement with B3LYP value The dihedral angle between C1-C7-N8-N6-C1in HF and B3LYP method are 181.583 and 181.562 (Fig. 1 (d)).

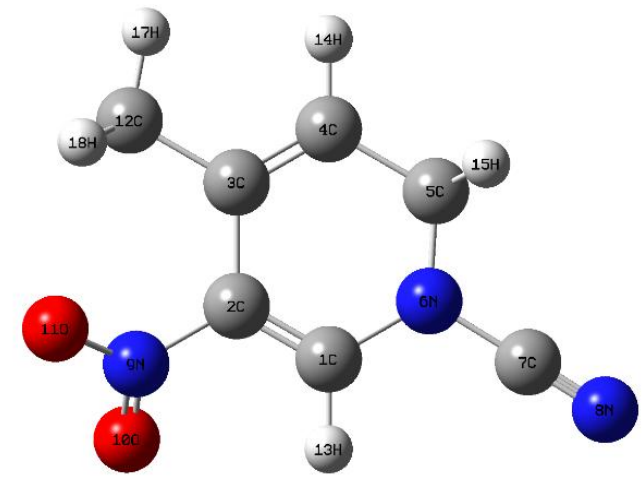

Fig 1(a). Optimized geometrical structure of 4-Methyl-3nitropyridine-1-carbonitrile

The calculated geometric parameters can be used to determine the other parameters of 4MNC. Bond angles and dihedral angles were referred from [24-26].

\subsection{Vibrational analysis}

The calculated frequencies using HF and B3LYP methods and their IR intensities and assignments, internal coordinates are listed in Table 2 and 3. The experimental FTIR, FT-Raman and calculated vibrational spectra (B3LYP) are shown in Figs. 2-3 respectively. The description of the various band assignments is as follows.

Table 1. Bond lengths (in Angstrom), bond angles (in degree) and dihedral angles (in degree) of the 4-Methyl-3nitropyridine-1-carbonitrile

\begin{tabular}{|c|c|c|}
\hline Parameters & $H F / 6-311++G(d, p)$ & DFT $/ 6-311++G(d, p)$ \\
\hline \multicolumn{3}{|c|}{ Bond length (Å) } \\
\hline $\mathrm{C} 1-\mathrm{C} 2$ & 1.2827 & 1.2981 \\
\hline C1-N6 & 1.3181 & 1.3381 \\
\hline $\mathrm{C} 1-\mathrm{C} 7$ & 1.4513 & 1.4411 \\
\hline $\mathrm{C} 2-\mathrm{C} 3$ & 1.3779 & 1.3846 \\
\hline $\mathrm{C} 2-\mathrm{H} 13$ & 1.0703 & 1.0804 \\
\hline $\mathrm{C} 3-\mathrm{C} 4$ & 1.3724 & 1.3841 \\
\hline C3-N9 & 1.473 & 1.4903 \\
\hline C4-C5 & 1.3952 & 1.4026 \\
\hline C4-14 & 1.0708 & 1.081 \\
\hline C5-6N & 1.3184 & 1.3378 \\
\hline C5-C12 & 1.5044 & 1.5034 \\
\hline 7C-N8 & 1.1291 & 1.1537 \\
\hline N9-010 & 1.1847 & 1.2211 \\
\hline N9-C11 & 1.1841 & 1.2207 \\
\hline $\mathrm{C} 12-\mathrm{C} 15$ & 1.0842 & 1.0928 \\
\hline C12-H16 & 1.0829 & 1.0904 \\
\hline C12-H17 & 1.0842 & 1.0928 \\
\hline \multicolumn{3}{|c|}{ Bond Angle(Å) } \\
\hline $\mathrm{C} 2-\mathrm{C} 1-6 \mathrm{~N}$ & 124.26 & 124.02 \\
\hline $\mathrm{C} 2-\mathrm{C} 1-7 \mathrm{C}$ & 119.14 & 119.27 \\
\hline $6 \mathrm{~N}-\mathrm{C} 1-7 \mathrm{C}$ & 116.59 & 116.70 \\
\hline
\end{tabular}

Ragavan et al., 


\begin{tabular}{|c|c|c|}
\hline $\mathrm{C} 1-\mathrm{C} 2-\mathrm{C} 3$ & 115.41 & 115.91 \\
\hline C1-C2-H13 & 122.17 & 122.42 \\
\hline C3-C2-H13 & 122.20 & 121.68 \\
\hline $\mathrm{C} 2-\mathrm{C} 3-\mathrm{C} 4$ & 121.6 & 121.56 \\
\hline C2-C3-N9 & 119.01 & 119.07 \\
\hline C4-C3-N9 & 119.25 & 119.36 \\
\hline C3-C4-C5 & 117.67 & 117.93 \\
\hline C3-C4-C14 & 120.74 & 120.27 \\
\hline C5-C4-C14 & 121.57 & 121.79 \\
\hline $\mathrm{C} 4-\mathrm{C} 5-6 \mathrm{~N}$ & 121.44 & 121.69 \\
\hline C4-C5-C12 & 121.62 & 121.60 \\
\hline $6 \mathrm{~N}-\mathrm{C} 5-\mathrm{C} 12$ & 116.92 & 116.70 \\
\hline C1-6N-C5 & 119.42 & 118.87 \\
\hline C3-N9-010 & 117.25 & 117.20 \\
\hline C3-N9-C11 & 117.07 & 117.18 \\
\hline 010-N9-C11 & 125.69 & 125.61 \\
\hline C5-C12-C15 & 109.79 & 109.95 \\
\hline C5-C12-H16 & 111.50 & 111.77 \\
\hline C5-C12-C17 & 109.79 & 109.96 \\
\hline C15-C12-H16 & 108.94 & 108.93 \\
\hline C15-C12-C17 & 107.76 & 107.14 \\
\hline N16-C12-C17 & 108.95 & 108.94 \\
\hline \multicolumn{3}{|c|}{ Dihedral Angle (Å) } \\
\hline C1-7C-N8-N6-C1 & 181.583 & 181.562 \\
\hline C1-7C-N8-N6-C2 & 180.0004 & 179.999 \\
\hline $6 \mathrm{~N}-\mathrm{C} 1-\mathrm{C} 2-\mathrm{C} 3$ & -0.0004 & -0.002 \\
\hline 6N-C1-C2-H13 & -180 & 179.998 \\
\hline 7C-C1-C2-C3 & 180.0005 & -180.00 \\
\hline 7C-C1-C2-H13 & 0.0011 & -0.0006 \\
\hline C2-C1-N6-C5 & 0.0003 & 0.0014 \\
\hline 7C-C1-N6-C5 & 179.9993 & 180.00 \\
\hline $\mathrm{C} 1-\mathrm{C} 2-\mathrm{C} 3-\mathrm{C} 4$ & 0.0005 & 0.0007 \\
\hline C1-C2-C3-N9 & -180.001 & 180.00 \\
\hline $\mathrm{H} 13-\mathrm{C} 2-\mathrm{C} 3-\mathrm{C} 4$ & -180 & -180 \\
\hline H13-C2-C3-N9 & -0.0015 & -0.0003 \\
\hline $\mathrm{C} 2-\mathrm{C} 3-\mathrm{C} 4-\mathrm{C} 5$ & -0.0005 & 0.001 \\
\hline C2-C3-C4-C14 & 179.9992 & 180.02 \\
\hline N9-C3-C4-C5 & 180.0009 & 180.0014 \\
\hline N9-C3-C4-C14 & 0.0006 & 0.0006 \\
\hline C2-C3-N9-010 & -179.994 & 179.99 \\
\hline C2-C3-N9-C11 & 0.0063 & -0.0209 \\
\hline C4-C3-N9-010 & 0.0048 & -0.0215 \\
\hline C4-C3-N9-C11 & -179.995 & 179.9787 \\
\hline (C3-C4-C5-6N & 0.0004 & -0.0017 \\
\hline
\end{tabular}

Ragavan et al., 


\begin{tabular}{|c|c|c|}
\hline & C3-C4-C5-C12 & -17 \\
\hline & C1C4-C4-C5-6N & 18 \\
\hline & C14-C4-C5-C12 & 0. \\
\hline & C4-C5-6N-C1 & -0 \\
\hline & C12-C5-6N-C1 & 17 \\
\hline & C4-C5-C12-C15 & 120 \\
\hline & C4-C5-C1C2-H16 & -0 \\
\hline & C4-C5-C12-C17 & -1 \\
\hline & 6N-C5-C12-C15 & -50 \\
\hline & $6 \mathrm{~N}-\mathrm{C} 5-\mathrm{C} 12-\mathrm{H} 16$ & 17 \\
\hline & 6N-C5-C12-C17 & 59 \\
\hline \multicolumn{3}{|c|}{$\begin{array}{l}\text { 3.2.1 C-C vibrations } \\
\text { The bands which indicate aromatic properties of } \\
\text { benzene derivatives mainly occur within the range of } \\
1640-1200 \mathrm{~cm}^{-1} \text {. The actual positions of these modes } \\
\text { are determined not so much by the nature of the } \\
\text { substituents but by the form of substitution around } \\
\text { the ring }[27,28] \text {. The medium to strong lines } \\
\text { calculated in the DFT and HF values of } 4 \mathrm{MNC} \text { at } 1612 \text {, } \\
1582,1456,1390,1336,1283 \text { and } 1233 \mathrm{~cm}^{-1} \text { and } \\
1623,1585,1573,1487,1454,1415 \text { and } 1368 \mathrm{~cm}^{-1} \\
\text { are assigned to the C-C stretching vibrations. }\end{array}$} \\
\hline
\end{tabular}

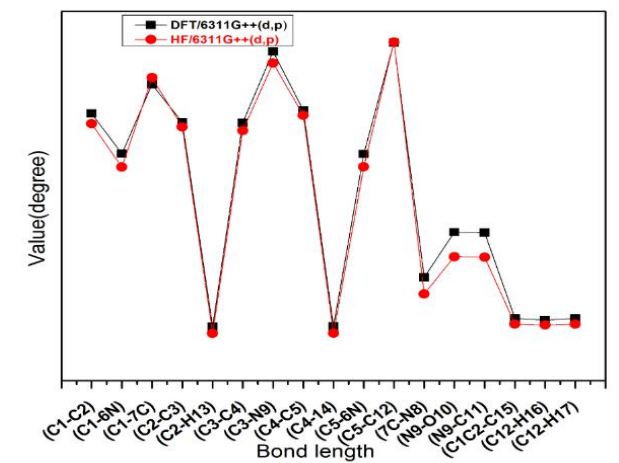

Fig 1(b). Bond length differences between HF and B3LYP approaches of the 4-Methyl-3-nitropyridine1-carbonitrile

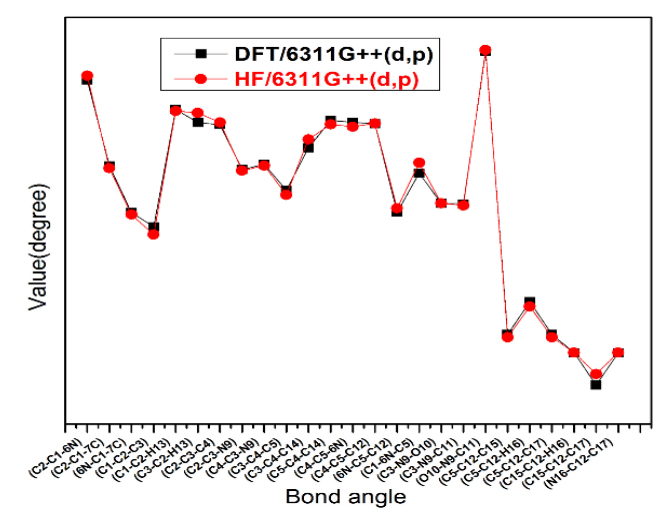

Fig 1(c). Bond angle differences between HF and B3LYP approaches of the 4-Methyl-3-nitropyridine1-carbonitrile

\begin{tabular}{|l|l|}
\hline 79.999 & -179.994 \\
\hline 0.0016 & -180.001 \\
\hline 0.0002 & 0.0067 \\
\hline 79.9989 & 0.0005 \\
\hline 0.8264 & 179.93 \\
\hline-0206 & 121.06 \\
\hline 9.1720 .87 & -0.0721 \\
\hline 79.9804 & -121.24 \\
\hline 9.1311 & -58.92 \\
\hline
\end{tabular}


have observed the C-N stretching vibration at 1375 $\mathrm{cm}^{-1}$ in pyridine. DFT calculations give the mode at $1266 \mathrm{~cm}^{-1}$. DFT calculations give the C-N stretching vibration at $2217 \mathrm{~cm}^{-1}$. In the present study, the theoretically computed values belonging to $\mathrm{C}-\mathrm{N}$ stretching vibrations are in agreement with spectral data. The calculations at HF and DFT levels give the frequency values of 3392, 1662 and $3410,1758 \mathrm{~cm}^{-1}$, respectively in $4 \mathrm{MNC}$ have been designed to $\mathrm{C}-\mathrm{H}$ stretching vibrations.

\subsubsection{C-H vibrations}

The hetroaromatic organic compound and its derivatives are structurally very close to benzene and commonly exhibit multiple weak bands in the region 3100-3000 $\mathrm{cm}^{-1}$ due to $\mathrm{C}-\mathrm{H}$ stretching vibration $[31,32]$. Table 2. The Calculated (Scaled) frequencies ( $\left.\mathrm{cm}^{-1}\right)$, IR intensity (Km mol-1), Raman intensity $\left(\mathrm{Km} \mathrm{mol}^{-1}\right)$ and
probable assignments (characterized by PED) of 4MNC using DFT and HF method of 6-311++G

(d,p)calculation.

\begin{tabular}{|c|c|c|c|c|c|c|c|c|}
\hline \multirow{2}{*}{ 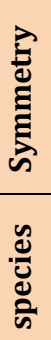 } & \multicolumn{2}{|c|}{$\begin{array}{l}\text { Scaled } \\
\text { Wavenumber } \\
\left(\mathrm{cm}^{-1}\right)\end{array}$} & \multirow{2}{*}{ 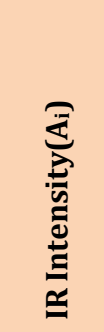 } & \multirow{2}{*}{ 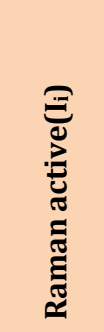 } & \multirow{2}{*}{ 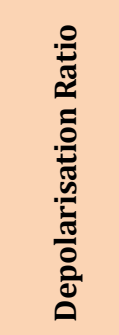 } & \multirow{2}{*}{ 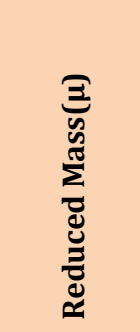 } & \multirow{2}{*}{ 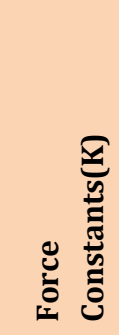 } & \multirow{2}{*}{$\begin{array}{l}\text { Assignments with PED\% } \\
\text { among types of coordinates }\end{array}$} \\
\hline & DFT & HF & & & & & & \\
\hline $\mathrm{A}^{\prime}$ & 3330 & 3414 & 0.280 & 0.509 & 0.7133 & 1.0125 & 0.1121 & $v \mathrm{CH}(99)$ \\
\hline$A^{\prime}$ & 3329 & 3410 & 3.270 & 0.545 & 0.7491 & 11.7380 & 0.0363 & $v$ NC (95) \\
\hline$A^{\prime}$ & 3327 & 3400 & 5.059 & 5.750 & 0.7485 & 10.6565 & 0.0588 & $v \mathrm{CH}(90)$ \\
\hline $\mathrm{A}^{\prime}$ & 3025 & 3080 & 0.038 & 0.764 & 0.7455 & 5.9446 & 0.0583 & $\beta$ HCC (69) v CH (30) \\
\hline $\mathrm{A}^{\prime}$ & 3070 & 3100 & 0.176 & 0.712 & 0.7423 & 3.0091 & 0.0537 & $v \mathrm{CH}(66)$ \\
\hline $\mathrm{A}^{\prime}$ & 2352 & 2427 & 1.736 & 0.464 & 0.6071 & 3.9239 & 0.0892 & $v$ ON (63) \\
\hline$A^{\prime}$ & 1662 & 1758 & 6.773 & 0.494 & 0.7496 & 7.0887 & 0.1933 & t HCCH (59) v NC (20) \\
\hline$A^{\prime}$ & 1612 & 1692 & 2.953 & 2.621 & 0.4653 & 5.3778 & 0.3001 & $\beta \mathrm{NC}(54), v \mathrm{CC}(45)$ \\
\hline $\mathrm{A}^{\prime}$ & 1589 & 1626 & 3.330 & 4.979 & 0.1033 & 8.3638 & 0.5708 & $v$ CC (53) \\
\hline $\mathrm{A}^{\prime}$ & 1456 & 1585 & 12.90 & 2.455 & 0.7450 & 5.9156 & 0.5098 & $\beta \mathrm{HCH}(52) \vee \mathrm{CC}(24)$ \\
\hline $\mathrm{A}^{\prime}$ & 1444 & 1573 & 2.030 & 1.992 & 0.7449 & 7.4457 & 0.7234 & t HCCC (52) \\
\hline$A^{\prime}$ & 1390 & 1487 & 2.053 & 8.669 & 0.2021 & 8.0727 & 0.9661 & $v \mathrm{CH}(50) v \mathrm{CC}(35)$ \\
\hline $\mathrm{A}^{\prime}$ & 1336 & 1454 & 0.292 & 0.140 & 0.5737 & 4.0237 & 0.6259 & $v$ CC (47) NC (23) \\
\hline $\mathrm{A}^{\prime}$ & 1283 & 1415 & 0.961 & 0.662 & 0.3739 & 5.6871 & 0.9229 & $v \mathrm{HCH}(47) \mathrm{CN}(34)$ \\
\hline $\mathrm{A}^{\prime}$ & 1233 & 1368 & 10.97 & 6.697 & 0.3635 & 6.1464 & 1.2011 & $v \mathrm{CC}(44) v \mathrm{CC}(13) v \mathrm{CH}(23)$ \\
\hline $\mathrm{A}^{\prime}$ & 1123 & 1368 & 0.533 & 1.396 & 0.7490 & 3.8637 & 0.8256 & v ON (44) \\
\hline$A^{\prime}$ & 1057 & 1149 & 10.45 & 0.326 & 0.6748 & 3.1917 & 0.9200 & $\beta \mathrm{HCH}(37)$ \\
\hline $\mathrm{A}^{\prime \prime}$ & 1006 & 1124 & 24.21 & 11.47 & 0.1577 & 12.9458 & 3.8495 & $\mathrm{t} \operatorname{CCCC}(36) v \operatorname{CC}(10)$ \\
\hline $\mathrm{A}^{\prime}$ & 1001 & 1099 & 2.387 & 1.837 & 0.7391 & 7.9967 & 2.5440 & $v \mathrm{CH}(35)$ \\
\hline $\mathrm{A}^{\prime}$ & 950 & 1022 & 7.394 & 3.460 & 0.6051 & 7.0339 & 2.3102 & $\beta$ ONO (35) v CC (12) \\
\hline $\mathrm{A}^{\prime}$ & 907 & 1019 & 26.11 & 31.39 & 0.1595 & 10.1484 & 3.5819 & $\beta \mathrm{CCN}(33)$ \\
\hline $\mathrm{A}^{\prime \prime}$ & 875 & 1010 & 0.366 & 2.852 & 0.2656 & 4.8667 & 1.8585 & $\beta_{\text {opb }}$ CCC (31) v CH (20) \\
\hline $\mathrm{A}^{\prime}$ & 873 & 1007 & 3.720 & 2.225 & 0.6922 & 1.5104 & 0.6784 & $v \mathrm{NC}(30)$ \\
\hline $\mathrm{A}^{\prime \prime}$ & 805 & 879 & 16.31 & 1.091 & 0.7462 & 1.6886 & 0.7634 & t HCCC (30) \\
\hline $\mathrm{A}^{\prime \prime}$ & 773 & 832 & 29.01 & 12.57 & 0.5022 & 2.8093 & 1.3639 & $\beta_{\text {opb }}$ CCC (29) v CH (20) \\
\hline $\mathrm{A}^{\prime \prime}$ & 746 & 807 & 18.13 & 7.232 & 0.2531 & 2.7695 & 1.4730 & $\beta_{\text {opb CCNC (29) }}$ \\
\hline A" & 734 & 791 & 21.47 & 12.57 & 0.4013 & 2.1475 & 1.2691 & $v \mathrm{NC}(28) \mathrm{CC}(18)$ \\
\hline $\mathrm{A}^{\prime \prime}$ & 710 & 782 & 97.08 & 37.87 & 0.3901 & 3.6546 & 2.1820 & $\begin{array}{c}\beta_{\mathrm{opb}} \mathrm{CCNC}(27) \vee \mathrm{CC}(10) \vee \mathrm{CH} \\
(25)\end{array}$ \\
\hline
\end{tabular}

Ragavan et al., 


\begin{tabular}{|c|c|c|c|c|c|c|c|c|}
\hline $\mathrm{A}^{\prime}$ & 699 & 695 & 23.03 & 22.07 & 0.4534 & 3.4662 & 2.2850 & $\beta N C C(26) \vee C H(22)$ \\
\hline$A^{\prime}$ & 602 & 682 & 44.02 & 6.540 & 0.3000 & 4.1988 & 3.1223 & $\beta \mathrm{CCN}(26) v \mathrm{CC}(11) \mathrm{CH}(22)$ \\
\hline A" & 575 & 638 & 25.31 & 2.092 & 0.6242 & 1.3988 & 1.2530 & t ONCC (26) $v$ CH (25) \\
\hline$A^{\prime}$ & 524 & 590 & 23.79 & 12.02 & 0.4301 & 1.8000 & 1.7467 & $v$ CCC (25) \\
\hline$A^{\prime}$ & 513 & 531 & 6.320 & 8.042 & 0.2213 & 1.2166 & 1.2795 & $\beta$ ONC (25) \\
\hline$A^{\prime}$ & 450 & 500 & 21.99 & 238.9 & 0.1199 & 7.3014 & 8.3186 & $v \mathrm{NC}(22)$ v ON (19) \\
\hline$A^{\prime}$ & 406 & 456 & 22.49 & 16.49 & 0.2828 & 1.0802 & 1.3283 & $v \mathrm{CC}(21) v \mathrm{NO}(15)$ \\
\hline$A^{\prime}$ & 382 & 419 & 11.36 & 9.436 & 0.5997 & 1.0478 & 1.3089 & $\beta$ CNC (21) \\
\hline$A^{\prime}$ & 340 & 383 & 7.201 & 36.54 & 0.7120 & 8.8271 & 13.1384 & $v$ CC (20) $v$ CC (17) \\
\hline A" & 307 & 335 & 258.2 & 77.42 & 0.2576 & 11.6444 & 17.8318 & $v$ OCON (19) v NO(15) \\
\hline$A^{\prime}$ & 215 & 278 & 30.49 & 6.540 & 0.6268 & 8.8377 & 14.3917 & $\beta_{\text {ipb }}$ CCC (18) \\
\hline$A^{\prime}$ & 196 & 250 & 0.719 & 339.3 & 0.2800 & 12.7678 & 41.6357 & $\beta$ NCC (16) v CH (12) \\
\hline $\mathrm{A}^{\prime \prime}$ & 174 & 235 & 3.763 & 210.1 & 0.0341 & 1.0317 & 6.3418 & t HCCC (16) \\
\hline $\mathrm{A}^{\prime \prime}$ & 128 & 229 & 6.160 & 65.75 & 0.6504 & 1.1034 & 7.1700 & t NCCC (15) \\
\hline A" & 96 & 199 & 5.346 & 52.11 & 0.2687 & 1.0935 & 7.1319 & t CCCN (12) \\
\hline$A^{\prime}$ & 72 & 189 & 0.300 & 73.70 & 0.6886 & 1.1035 & 7.2060 & $v$ CC $(10)$ \\
\hline$A^{\prime \prime}$ & -433 & -351 & 9.700 & 43.35 & 0.2795 & 1.0923 & 7.1403 & t $\operatorname{HCCC}(10)$ \\
\hline
\end{tabular}

$v \rightarrow$ Stretching,$\quad \beta \rightarrow$ Bending,$\quad \beta_{\text {opd }} \rightarrow$ Out-of-plane-bending,$\quad \beta_{\text {ipd }} \rightarrow$ in-plane-bending, $\quad t \rightarrow$ torsion.

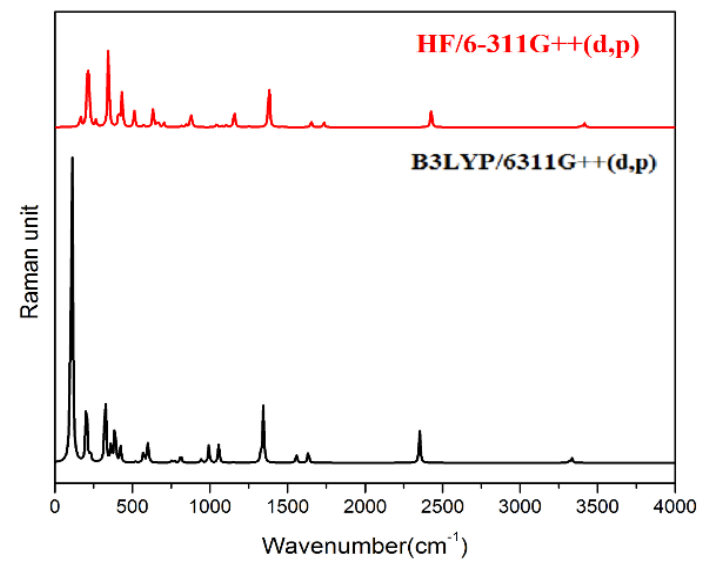

Fig 3. Calculated FT-Raman Spectra of 4Methyl-3-nitropyridine-1-carbonitrile

In the title molecule, the very strong intensity band calculated wavenumbers are at 3025, 3070and 3080, $3100 \mathrm{~cm}^{-1}$ at DFT/B3LYP and HF method with 6$311++\mathrm{G}(\mathrm{d}, \mathrm{p})$ basis set respectively. The theoretically calculated $\mathrm{C}-\mathrm{H}$ vibrations by DFT/B3LYP and HF method of scaled values are given Table 2 .

\subsection{Frontier molecular orbitals}

Highest occupied molecular orbital (HOMO) and lowest unoccupied molecular orbital (LUMO) are very important parameters for quantum chemistry. The energies of HOMO, LUMO, LUMO+1 and HOMO-1 and their orbital energies are calculated using B3LYP/6$311++G(d, p)$ method and the pictorial illustration of the frontier molecular orbitals are shown in Fig. 4.

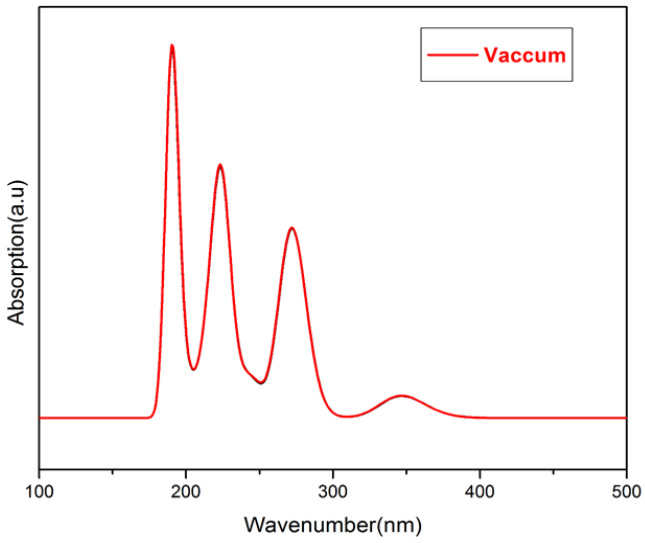

Fig 5. Calculated electronic absorption spectra of the 4-Methyl-3-nitropyridine-1-carbonitrile

Molecular orbitals provide insight into the nature of reactivity and some of the structural and physical properties of molecules. The positive and negative phase is represented in red and green colour, respectively. The plots reveal that the region of HOMO spread over the entire molecule of 4MNC while in the case of LUMO it is spread over the entire molecule except on nitrile group. The calculated energy gap of HOMO-LUMO's explains the ultimate charge transfer interface within the molecule. The energies of the frontier molecular orbitals of 4MNC employing DFT/B3LYP method using 6-311++G (d, p) basis set. The frontier orbital energy gap calculated by B3LYP method (E $\mathrm{E}_{\text {Lumo }} \mathrm{E}_{\text {номо }}$ ) in case of $4 \mathrm{MNC}$ is found to be is $4.7648 \mathrm{eV}$. 


\subsection{Absorption spectral analysis}

The UV-Vis absorption spectrum of $4 \mathrm{MNC}$ recorded in water is shown in Fig. 5. Molecules allow strong $\pi \rightarrow \pi^{*}$ transition in the UV-visible region with high extinction coefficients [33]. NBO analysis indicates that molecular orbitals are mainly composed of $\pi$ and $\sigma$ atomic orbital. TD-DFT/6-311++G $(d, \quad p)$ calculations have been used to determine the low lying excited states of 4MNC. The calculated excitation energies, absorbance and oscillator strength (f) for the title molecule are tabulated in Table 4. The maximum absorption peak $\left(\lambda_{\max }\right)$ in the UV-vis spectrum predicts electronic transition at $309 \mathrm{~nm}$ with an oscillator strength $\mathrm{f}=0.0004$.

Table 3 Definition of internal coordinates of 4-Methyl-3-nitropyridine-1-carbonitrile.

\begin{tabular}{|c|c|c|c|}
\hline NO & Symbols & Type & Definition \\
\hline \multicolumn{4}{|c|}{ Stretching } \\
\hline $1-5$ & $\mathrm{ri}_{\mathrm{i}}$ & CH (methyl) & C12-H15,C12-H16,C12H17, C4-H14,C2-H13 \\
\hline $6-9$ & $\mathrm{Q}_{\mathrm{i}}$ & NC & N6-C1,N9-C3,N6-C5,N8-C7 \\
\hline $10-13$ & $\mathrm{R}_{\mathrm{i}}$ & CC(aromatic) & $\mathrm{C} 1-\mathrm{C} 2, \mathrm{C} 2-\mathrm{C} 3, \mathrm{C} 3-\mathrm{C} 4 . \mathrm{C} 4-\mathrm{C} 5$ \\
\hline 14-15 & $\mathrm{Pi}_{\mathrm{i}}$ & NO & N9-010,N9-011 \\
\hline 16 & $\mathrm{q}_{\mathrm{i}}$ & $\mathrm{CC}$ & C1-C7 \\
\hline \multicolumn{4}{|c|}{ Bending } \\
\hline $17-18$ & $\beta_{\mathrm{i}}$ & Ring & C1-C2-C3,C3-C4-C5 \\
\hline 19 & $\delta_{\mathrm{i}}$ & ONO & 010-N9-011 \\
\hline $20-22$ & $\alpha_{\mathrm{i}}$ & $\mathrm{HCH}$ & H15-C12-C16, H16-C12-C17, H17-C12-C15 \\
\hline $23-24$ & $\sigma_{\mathrm{i}}$ & NCC & N9-C3-C4,N6-C5-C4 \\
\hline $25-26$ & $\varphi_{\mathrm{i}}$ & HCC & H14-C4-C5,H13-C2-C1 \\
\hline $27-28$ & $\theta_{\mathrm{i}}$ & $\mathrm{CCN}$ & C2-C1-6N,C4-C3-N9 \\
\hline 30 & $\delta_{\mathrm{i}}$ & ONC & 011-N9-C3 \\
\hline 31 & $\pi_{\mathrm{i}}$ & $\mathrm{CNC}$ & 011-N9-C3 \\
\hline \multicolumn{4}{|c|}{ Linear bending } \\
\hline 29 & $\pi_{\mathrm{i}}$ & NCC & N9-C7-C1 \\
\hline \multicolumn{4}{|c|}{ Out-of-plan bending } \\
\hline 32 & $\prod_{1}$ & ONC & 011-C3-010-N9 \\
\hline 33 & $\omega_{1}$ & $\mathrm{CN}$ & C2-C1-N6-C5 \\
\hline 34 & $\omega_{1}$ & $\mathrm{CC}$ & N9-C3-C2-C1 \\
\hline 35 & $\omega_{1}$ & $\mathrm{CN}$ & C4-C5-N6-C1 \\
\hline \multicolumn{4}{|c|}{ Torsion } \\
\hline 36 & $t_{i}$ & $\tau\left(\mathrm{H}-\mathrm{CN}_{2}\right)$ & H14-C4-C3-N9 \\
\hline $37-40$ & $t_{i}$ & $\tau\left(\mathrm{Car}-\mathrm{H}_{3}\right)$ Ring & $\begin{array}{c}\mathrm{H} 13-\mathrm{C} 2-\mathrm{C} 3-\mathrm{C} 4, \mathrm{H} 15-\mathrm{C} 12-\mathrm{C} 5-\mathrm{C} 4, \mathrm{H} 16-\mathrm{C} 12-\mathrm{C} 5- \\
\text { C4, H17-C12-C5-C4 }\end{array}$ \\
\hline 41 & $t_{i}$ & $\tau(\mathrm{CC})$ Ring & $\mathrm{C} 5-\mathrm{C} 4-\mathrm{C} 3-\mathrm{C} 2$ \\
\hline 42 & $t_{i}$ & $\tau(\mathrm{NC})$ & N6-C1-C2-C3 \\
\hline 43 & $t_{i}$ & $\tau(\mathrm{CN})$ & C1-N6-C5-C4 \\
\hline 44 & $t_{i}$ & $\tau(\mathrm{ON})$ & 011-N9-C3-C4 \\
\hline 45 & $t_{i}$ & $\tau(\mathrm{CN})$ & C2-C1-C7-N9 \\
\hline
\end{tabular}

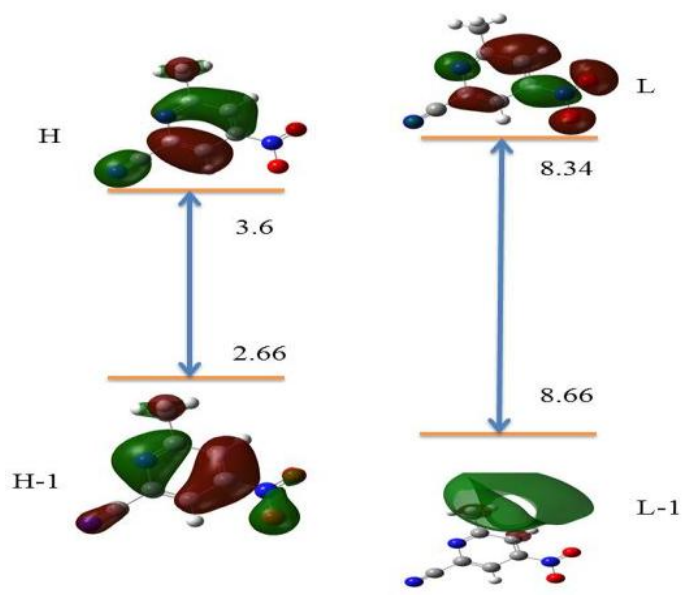

Fig 4. Isodensity plots (isodensity contour = 0.03 a.u.) of the frontier orbitals of 4-Methyl-3-nitropyridine-1carbonitrile

Ragavan et al., 
The wavelengths obtained with DFT/B3LYP/6$311++G(d, p)$ computations are 409, 372 and $346 \mathrm{~nm}$ (in Vaccum). Both HOMO and LUMO are the main orbitals that take part in chemical stability. In view of calculated absorption spectra, the wavelength 409 , 372 and $346 \mathrm{~nm}$ corresponds to the electronic transition from the HOMO-1 to LUMO with $94 \%$ contribution, from HOMO to LUMO+1 with 93\% contribution and HOMO to LUMO with 85\% contribution respectively.

\subsection{First order polarizability and hyper polarizability}

NLO techniques are considered as among the most structure sensitive methods to study the molecular structures [34] and the computational approach allows the determination of molecular NLO properties as an inexpensive way to design molecules by analyzing the potential before synthesis and to determine high-order hyperpolarizability tensors of molecules. In the recent years, because of potential applications in modern communication technology, data storage, telecommunication, dependent on the efficiency of electronic communication between acceptor and the donor groups as that will be the key to intramolecular charge transfer $[37,38]$.

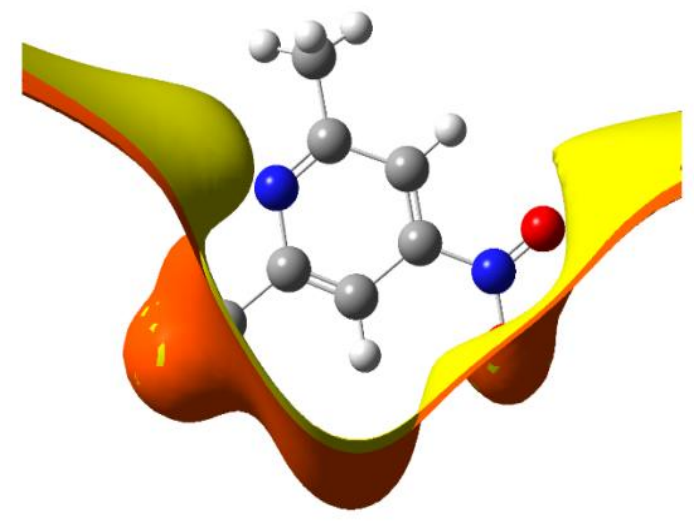

Fig.6. Electrostatic potential map 4-Methyl-3nitropyridine-1-carbonitrile

The acceptor and donor groups have an important role in the polarizability and first hyperpolarizability is tensor components of hyperpolarizability.

The definitions for the isotropic polarizability is

$$
\alpha=\frac{1}{3}\left(\alpha_{X X}+\alpha_{Y Y}+\alpha_{Z Z}\right)
$$

The polarizability anisotropy invariant is

$\Delta \alpha=\left[\frac{\left(\alpha_{X X}-\alpha_{Y Y}\right)^{2}+\left(\alpha_{Y Y}-\alpha_{Z Z}\right)^{2}+\left(\alpha_{Z Z}-\alpha_{X X}\right)^{2}}{2}\right]$ and the average hyperpolarizability is $\beta_{t o t}=\left(\beta_{x}^{2}+\beta_{y}^{2}+\beta_{z}^{2}\right)^{1 / 2}$

Where,

$$
\begin{aligned}
& \beta_{x}=\beta_{x x x}+\beta_{y y y}+\beta_{z z z} \\
& \beta_{y}=\beta_{y y y}+\beta_{x x y}+\beta_{y z z} \\
& \beta_{z}=\beta_{z z z}+\beta_{x x z}+\beta_{y y z}
\end{aligned}
$$

Where, $\alpha_{X X}, \alpha_{Y Y}$, and $\alpha_{Z Z}$ are tensor components of polarizability; $\beta_{i i z}, \beta_{i Z i}$ and $\beta_{Z i i}$ (i from X to Z)

The large value of first hyperpolarizability, which is the measure of the NLO activity of the molecular system, is associated with the Intra molecular Charge Transfer (ICT), resulting from the electron cloud movement through conjugated frame work from electron donor to electron acceptor groups. The polar properties of the title molecule were calculated at the DFT and HF/6-311++G (d, p) level. Theoretical investigation plays an important role in understanding the structure property relationship which is able to assist in designing novel NLO materials. Theoretically, calculated values of dipole Moment $(\mu)$, polarizability $(\alpha)$, anisotropic tensor and hyperpolarizability $(\beta)$ are shown in Table 5.

\subsection{MEP analysis}

Molecular electrostatic potential (MEP) mapping is very useful in the investigation of the molecular structure with its physiochemical property relationships [39, 40]. Total SCF electron density surface mapped with molecular electrostatic potential (MEP) of 4MNC determined by DFT/B3LYP/6$311++G(d, p)$ method is shown in Fig. 6(a) while the contour map of the molecular electrostatic potential is given in Fig. 6(b). The MEP surface displays the molecular shape, size and electrostatic potential values.

The colour scheme for the MEP surface is red-electron rich or partially negative charge; blue-electron deficient or partially positive charge; light blueslightly electron deficient region; yellow- slightly electron rich region, respectively. The oxygen atoms have more negative potentials and the hydrogen atoms have more positive potentials. The extreme limits of the electron density observed in 4MNC are $\pm 3.201 \mathrm{e}$. The MEP of 4MNC clearly indicates the electron rich centres of oxygen atoms. The Molecular electrostatic potential surface of 4MNC determined by DFT/B3LYP/6-311++G (d, p) method is shown in the supplementary Fig

\subsection{Thermodynamic properties}

The theoretical thermodynamic parameters, rotational constants, rotational temperature, dibrational temperature and dipole moment have been presented in Table 6 . Scale factors have been recommended [41] for an accurate prediction in determining the Zero-Point Vibration Energies (ZPVE) and the entropy, $S_{\mathrm{vib}}(\mathrm{T})$ and the molar capacity at constant volume were calculated. The variations in the ZPVEs seem to be significant. The ZPVE is much lower by the DFT (B3LYP) method than by HF method. The biggest value of ZPVE $4 \mathrm{MNC}$ is $70.26827 \mathrm{Kcal} / \mathrm{mol}$ obtained at $\mathrm{HF} / 6-311+\mathrm{G}$ (d,p) whereas the smallest value is $75.30679 \mathrm{Kcal} / \mathrm{mol}$ obtained at B3LYP/6-311+G(d,p).

Ragavan et al., 
Table 4. Computed excitation energies, electronic transition configurations and oscillator strengths (f) for the optical transitions with $f>0.01$ of the absorption bands in visible and near- UV region for the 4-Methyl-3nitropyridine-1-carbonitrile.

\begin{tabular}{|c|c|c|c|c|}
\hline $\begin{array}{c}\text { Excited } \\
\text { state }\end{array}$ & $\begin{array}{c}\text { Wavelength } \\
\boldsymbol{\lambda} \mathbf{( n m})\end{array}$ & $\begin{array}{c}\text { Excitation } \\
\text { energy(eV) }\end{array}$ & $\begin{array}{c}\text { Oscillator } \\
\text { strength(f) }\end{array}$ & Major contributions \\
\hline S1 & 409 & 24427 & 0.0032 & $\mathrm{H}-2->\mathrm{L}(93 \%) \mathrm{H}->\mathrm{L}(3 \%)$ \\
\hline S2 & 372 & 26877 & 0.0006 & $\mathrm{H}-1->\mathrm{L}(13 \%), \mathrm{H}->\mathrm{L}(81 \%)$ \\
\hline S3 & 346 & 28875 & 0.0299 & $\mathrm{H}-1->\mathrm{L}(85 \%), \mathrm{H}->\mathrm{L}(13 \%)$ \\
\hline S4 & 309 & 32267 & 0.0004 & $\mathrm{H}-5->\mathrm{L}(96 \%)$ \\
\hline S5 & 271 & 36783 & 0.2554 & $\mathrm{H}-4->\mathrm{L}(18 \%), \mathrm{H}-3->\mathrm{L}(79 \%)$ \\
\hline S6 & 263 & 37959 & 0.0005 & $\mathrm{H}-1->\mathrm{L}+1(16 \%), \mathrm{H}->\mathrm{L}+1(82 \%)$ \\
\hline S7 & 243 & 41045 & 0.0517 & $\mathrm{H}-4->\mathrm{L}(76 \%), \mathrm{H}-3->\mathrm{L}(18 \%)$ \\
\hline S8 & 225 & 44380 & 0.0077 & $\mathrm{H}-1->\mathrm{L}+2(12 \%), \mathrm{H}->\mathrm{L}+2(81 \%)$ \\
\hline S9 & 223 & 44648 & 0.2966 & $\mathrm{H}-1->\mathrm{L}+1(67 \%), \mathrm{H}-1->\mathrm{L}+2(23 \%)$ \\
\hline S10 & 222 & 44958.4 & 0.001 & $\mathrm{H}-2->\mathrm{L}+1(96 \%)$ \\
\hline
\end{tabular}

Table 5. Polarizability (X10-24esu) and Hyper polarizability $\beta\left(X 10^{-31}\right.$ esu) of the $4 M N C$ molecule calculated at the DFT and HF method of 6-311++G $(d, p)$ level.

\begin{tabular}{|c|c|c|}
\hline$*$ & $\begin{array}{c}\text { DFT/6- } \\
311 G++(d, p\end{array}$ & $\begin{array}{c}\mathrm{HF} / 6- \\
311 \mathrm{G}++(\mathrm{d}, \mathrm{p})\end{array}$ \\
\hline \multicolumn{3}{|c|}{ Polarizability $(\alpha)$} \\
\hline $\boldsymbol{\alpha}_{\mathrm{xx}}$ & 95.29 & 97.05 \\
\hline$\alpha_{\mathrm{xy}}$ & 5.521 & 5.626 \\
\hline$\alpha_{y y}$ & 67.20 & 67.55 \\
\hline$\alpha_{\mathrm{xz}}$ & 0.0 & 0.0 \\
\hline$\alpha_{\mathrm{yz}}$ & 0.0 & 0.0 \\
\hline$\alpha_{\mathrm{zz}}$ & 67.04 & 67.46 \\
\hline$\alpha(\mathrm{esu})$ & 76.51570001 & 77.3614000 \\
\hline$\Delta \alpha($ esu) & 28.17500842 & 29.5446784 \\
\hline \multicolumn{3}{|c|}{ Hyperpolarizability $(\beta)$} \\
\hline $\boldsymbol{\beta}_{\mathrm{xxx}}$ & -39.9 & -39.5 \\
\hline$\beta_{\mathrm{xxy}}$ & 42.7 & 44.7 \\
\hline$\beta_{x y y}$ & -19.95 & -2042 \\
\hline$\beta_{\text {yyy }}$ & 39.19 & 40.41 \\
\hline$\beta_{\mathrm{xxz}}$ & -0.0 & 0.0 \\
\hline$\beta_{\mathrm{xyz}}$ & 0.0 & 0.0 \\
\hline$\beta_{\mathrm{yyz}}$ & 0.0022 & 0.0 \\
\hline$\beta_{\mathrm{xzz}}$ & -9.172 & -9.522 \\
\hline$\beta_{\mathrm{yzz}}$ & -0.82 & -0.68 \\
\hline$\beta_{\mathrm{zzz}}$ & 0.0031 & 0.0007 \\
\hline $\boldsymbol{\beta}_{\mathrm{ii} \text { (esu) }}$ & 106.5585929 & 109.3890715 \\
\hline Dipole moment & 5.2946 & 6.1999 \\
\hline
\end{tabular}

Table 6. Theoretically computed zero-point vibrational energy (Kcal mol-1), rotational constants (GHz), rotational temperatures (Kelvin), thermal energy (Kcal mol-1), molarcapacity at constant volume (cal mol-1

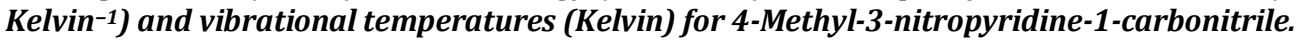

\begin{tabular}{|c|c|c|}
\hline Parameter & DFT/B3LYP & HF \\
\hline Zero-point vibrational energy & 70.26827 & 75.30679 \\
\hline Rotational constant (GHZ) & 1.19510 & 1.19510 \\
\hline & 0.68893 & 0.68893 \\
\hline & 0.43818 & 0.43818 \\
\hline Rotational temperature (Kelvin) & 0.05736 & 0.05736 \\
\hline & 0.03306 & 0.03306 \\
\hline & 0.02103 & 0.02103 \\
\hline Energy total (KCal/Mol) & 76.646 & 80.815 \\
\hline Translational(KCal/Mol) & 0.889 & 0.889 \\
\hline Rotational(KCal/Mol) & 0.889 & 0.889 \\
\hline Vibrational(KCal/Mol) & 74.868 & 79.038 \\
\hline
\end{tabular}

Ragavan et al., 


\begin{tabular}{|c|c|c|}
\hline Vibrational temperature (Kelvin) & 104.30 & 272.17 \\
\hline & 139.23 & 286.57 \\
\hline & 185.57 & 330.41 \\
\hline & 250.42 & 338.56 \\
\hline & 282.60 & 359.78 \\
\hline & 309.55 & 400.38 \\
\hline & 442.80 & 483.38 \\
\hline & 489.67 & 552.20 \\
\hline & 550.28 & 603.91 \\
\hline & 584.25 & 656.67 \\
\hline & 648.46 & 719.95 \\
\hline & 739.29 & 765.42 \\
\hline & 755.11 & 848.97 \\
\hline & 828.60 & 919.29 \\
\hline & 866.45 & 981.43 \\
\hline & 1006.39 & 1000.58 \\
\hline & 1022.13 & 1126.14 \\
\hline & 1057.25 & 1139.33 \\
\hline & 1074.23 & 1161.86 \\
\hline & 1113.58 & 1197.53 \\
\hline & 1158.33 & 1264.98 \\
\hline & 1256.23 & 1449.14 \\
\hline & 1260.30 & 1453.63 \\
\hline & 1306.04 & 1467.54 \\
\hline & 1366.98 & 1471.47 \\
\hline & 1440.97 & 1582.39 \\
\hline
\end{tabular}

phase and in different solvent systems using polarizable continuum model (PCM) to calculate the

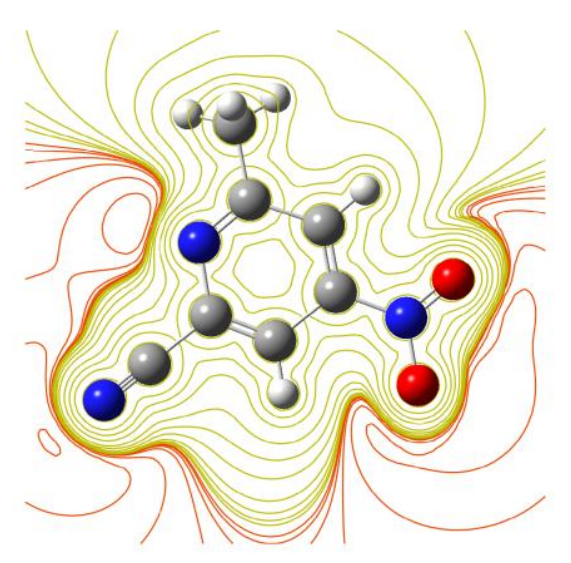

Fig 6(b) Electrostatic potential contour map 4Methyl-3-nitropyridine-1-carbonitrile

\section{CONCLUSION}

In this work, we have used the DFT/B3LYP and HF methods to investigate theoretical analysis on the geometries and electronic properties of 4-Methyl-3nitropyridine-1-carbonitrile. The geometry was optimized and bond lengths and bond angles were obtained by HF and DFT methods. It may be pointed out that the bond lengths obtained by both HF and DFT/B3LYP methods are comparable and the bond lengths obtained by B3LYP method are slightly longer than those calculated by $\mathrm{HF}$ method. Further investigations on the molecular structure and spectroscopy properties were done using HF and DFT calculations at B3LYP/6-311+G (d,p) level of theory. TD-DFT calculations were carried out in both the gas electronic absorption spectra. The mean polarizability and total first static hyperpolarizability of the molecule under investigation are found to be 29.5446784 X 10-24 e.s.u. and 6.1999 X10-30 e.s.u., respectively. The theoretical investigations of thermodynamic properties and energies of HOMO and LUMO orbitals which can be used to predict the conversion of biological and solar cell applications of this compound.

\section{ACKNOWLEDGEMENTS}

The authors are thankful to the learned referees for their useful and critical comments, which can be improved the quality of the manuscript.

\section{REFERENCES}

[1]. Pozharskii, A.F., Soldatenkov, A.T., Katritzky, A.R. ,1997.Heterocycles in Life and Society, John Wiley and Sons, UK, pp. 185-202.

[2]. Xu, J., Stevenson, J., 2000. Drug-like index: a new approach to measure drug-like compounds and their diversity. Computational Science, 40, 11771185.

[3]. Ishaat Khan, M.v., Afaq. A., 2010. Synthesis, spectral and thermal studies of the newly hydrogen bonded charge transfer complex of ophenylenediamine with $\pi$ acceptor picric acid. J. Spectrachimica Acta, 77, 437-441.

[4]. Nessreen Hashimi, A.A., Yasser Hussein, H.A., 1995. Ab initio study on the formation of triiodide CT complex from the reaction of iodine with 2, 3-diaminopyridineJ. Spectrochimica Acta, 77,198-202.

[5]. Lizarraga, M.E., Navarro, R., Urriolabeitia, E.P., Synthesis and characterization of dinuclear

\section{Ragavan et al.,}


complexes of PdII containing the $(\mu-\mathrm{NCS})_{2}$ skeleton, 1997. Organic Metal Chemistry, 542, 51-60.

[6]. Georgopoulou, A.S., Ulvenlund, S., Mingos, D.M.P., Baxter, I., Williams, D.J., 1999. Synthesis of water soluble DTPA complexes with pendant uracil moieties capable of forming complementary hydrogen bonds. American Chemical Society, 4,547-552.

[7]. Liaw, W., Lee, N., Chen, C., Lee, C., Lee, G., Peng, S., 2000. Dinuclear and mononuclear iron (II)thiolate complexes with mixed $\mathrm{CO} / \mathrm{CN}$-ligands: synthetic advances for iron sites of [Fe]-only hydrogenases. American Chemical Society, 122,488-496.

[8]. Trotter, P.J., White, P.A., 1978. Resonance Raman determination of the triiodide structure in bis (tetrathiotetracene) triiodide organic conductor compared with the poly (vinyl alcohol)-iodine complex. Applied Spectroscopy, 32,323-324.

[9]. Rajpure, K.Y., Bhosale, C.H., $\mathrm{Sb}_{2} \mathrm{~S}_{3}$ semiconductor-septum rechargeable storage cell. 2000. Materials Chemistry and Physics. 64,70-74.

[10]. Yen-Ju, C., Sheng-Hsiung, Y., Chain-Shu, H., 2009. Synthesis of conjugated polymers for organic solar cell applications. Chemical Revision, 109, 5868-5923.

[11]. Guoqiang Wang, Jia Cao, Liuzhou Gao, Wenxin Chen, Wenhao Huang, Xu Cheng and Shuhua, 2017. Metal-Free Synthesis of C-4 Substituted Pyridine Derivatives Using Pyridine-boryl Radicals via a Radical Addition/Coupling Mechanism: A Combined Computational. American Chemical Society, 139, 3904-3910.

[12]. Kandasamy, M., Velraj, G., 2012. Molecular structure and vibrational spectra of 3-and 4amino-2-bromopyridine by density functional methods. Spectrochimica Acta, 91,206- 216.

[13]. Sundaraganesan, N., Illakiamani, S., Anand, B., Saleem, H., Joshua, B.D., 2006. FTIR, FT-Raman spectra and ab initio DFT vibrational analysis of 2-amino-5-chloropyridine, Spectrochimica Acta, 64, 586-594.

[14]. Sundaraganesan, N., Meganathan, C., Anand, B., Joshua, B.D., Lapouge, C., 2007. FTIR, FT-Raman spectra and ab initio DFT vibrational analysis of 2-amino-5-chloropyridine, Spectrochimica Acta, 67, 830-835.

[15]. Sundaraganesan, N., Kalaichelvan, S., Meganathan, C., Joshua, B.D., Cornard, J.P., 2008. FT-IR, FT-Raman spectra and ab initio HF and DFT calculations of 4-N, N' -dimethylamino pyridine. Spectrochimica Acta, 71, 898-906.

[16]. Sundaraganesan, N., Meganathan, C., Kurt, M., 2008. Molecular structure and vibrational spectra of 2-amino-5-methyl pyridine and 2amino-6-methyl pyridine by density functional methods. Molecular Structure, 891, 284-291.

[17]. Frisch, J., Trucks, G.W., Schlegel, H.B., Scuseria, G.E., Robb, M.A., Cheeseman, J.R., Nakatsuji,H., Caricato, M., Li, X., Hratchian, H.P., Toyota, K., Fukuda, R., Hasegawa, J., Ishida, M., Nakajima, R., Honda, Y., Kilao, O., Nakai, H., Verven, T., Montgomery, J.A, Peralta,F., Ogliaro, M.,
Bearpark, J.J., Heyd, E., Brothers, K.N., Kudin, V.N. , Staroveror, Jr. , Kobayashi, R., Normand, J., Ragavachari, K. , Rendell, A., Burant, J.C., Tomasi, S.J., Cossi, M., Rega, N., Millam, J.M., Klene, M., Knox,J.E. , Cross, J.B., Bakken, V., Adamo, C., Jaramillo, J., Gomperts, R., Strattmann, R.E., Yazyev, O., Austin, A.J., Cammi, R., Ochetrski,J.W., Martin, R.L., Morokuma, K., Zakrazawski, V.G., Votn, G.A., Salvador, P., Dannenberg, J.J., Dapprich, S., Daniels, A.D., Farkas, O., Foresman, J.B., Gaussian O.G., (2009). Revision A.02, Gaussian Inc., Wallingford, CT.

[18]. Becke, A.D., 1993. The X3LYP extended density functional for accurate descriptions of nonbond interactions, spin states, and thermochemical properties. Chemical Physics, 98, 5648-5652.

[19]. Lee, C., Yang, W., Parr, R.G., Development of the Colle-Salvetti correlation-energy formula into a functional of the electron density. 1998. Physical Revision, 1377, 785-789.

[20]. Frisch, M.J., Nielsm, A.B., Holder, A.J. 2008. Gaussview User Manual, Gaussian Pitsburgh.

[21]. Baker, J., Jarzecki, A.A., Pulay, P., 1998. Direct scaling of primitive valence force constants: an alternative approach to scaled quantum mechanical force fields. Physical Chemistry, 102, 1412-1419.

[22]. Pulay, P., Fogarasi, G., Pang, F., Boggs, J.E., 1979. Systematic ab initio gradient calculation of molecular geometries, force constants, and dipole moment derivatives. American Chemical Society, 101, 2550- 2560.

[23]. Sundius, T., 1990. Molvib-A flexible program for force field calculations. Molecular Structure, 218, 321-326.

[24]. Muthu, S., Uma Maheswari, J., 2012. Quantum mechanical study and spectroscopic (FT-IR, FT-Raman, 13 C, $1 \mathrm{H}, \mathrm{UV}$ ) study, first order hyperpolarizability, NBO analysis, HOMO and LUMO analysis of 4-[(4-aminobenzene) sul fonyl] aniline Spectrochim. Acta 92, 154-163.

[25]. Muthu, S., Elamurugu Porchelvi, E., 1152013. FTIR, FT-RAMAN, NMR, spectra, normal coordinate analysis, NBO, NLO and DFT calculation of N, N-diethyl-4methylpiperazine-1-carboxamide molecule. Spectrochimica Acta, 115,275-286.

[26]. Santhana Krishnan, V., Sampath Krishnan, S., Muthu, S., Renuga, S., (2013). Experimental and computational study on molecular structure and vibrational analysis of 4, 5-Bis (hydroxymethyl)-2-methylpyridin-3-ol by normal coordinate treatment. Spectrochimica Acta, 115, 191-201.

[27]. Bellamy, L.J., 1975.The Infrared Spectra of Complex Molecules, third ed., Wiley, New York, 1, pp 433.

[28]. Varsanyi, G., 1974. Assignments for Vibrational Spectra of Seven Hundred Benzene Derivatives. Adam Hilger, London, pp96-106.

[29]. Gunasekaran, S., Thilak Kumar, R., Ponnusamy, S., Vibrational spectra and normal coordinate analysis of diazepam, phenytoin and phenobarbitone, 2006. Spectrochimica Acta 
Part A, Molecular and Biomolecular Spectroscopy, 65, 1041-1052.

[30]. Krishnakumar, V., John Xavier, R., 2003. Normal coordinate analysis of 2-mercapto and 4, 6-dihydroxy-2-mercapto pyrimidines. Applied Physics, 41,597-601.

[31]. Scott, A.P., Radom, L., 1996. Harmonic vibrational frequencies: an evaluation of Hartree- Fock, Møller- Plesset, quadratic configuration interaction, density functional theory and semiempirica. Physical Chemistry, 100, 16502-16513.

[32]. Udhayakala, P., Rajendiran, T.V., Seshadri, S., Gunasekaran, S., 2011. Quantum chemical vibrational study, molecular property and HOMO-LUMO energies of 3-bromoaceto phenone, Chemical and Pharmaceutical Research, 33, 610-625.

[33]. Senthilkumar, P., Nithya C., Anbarasanv P. M., 2013. 2, 3'-Diamino-4,4'-stilbenedicarb oxylic acid sensitizer for dye-sensitized solar cells: quantum chemical investigations. J Mol Model 19, 4561-4573.

[34]. Jesintha John, C., Amalanathan, M., Twinkle, A.R., Srinivasan, P., Hubert Joe, I., 2011. Vibrational spectra and first order hyperpolarizability studies of dimethyl amino pyridinium 4-nitrophenolate 4-nitrophenol. Spectrochimica Acta, 81, 151-161.

[35]. Zhang, R., Dub, B., Sun, G., Sun, Y., 2010. Experimental and theoretical studies on o-, m- and p-chlorobenzylideneaminoantipyrine. Spectrochimica Acta, 75, 1115-1124.

[36]. Yazici, S., Albayrak, C., Gumrukcuoglu, I., Buyukgungor, 0., 2011. Experimental and density functional theory (DFT) studies on (E)2-Acetyl-4-(4-nitrophenyldiazenyl) phenol. Molecular Structure, 985, 292-298.

[37]. Kosar, B., Albayrak, C., 2011. Spectroscopic investigations and quantum chemical computational study of (E)-4-methoxy-2-[(ptolylimino) methyl] phenol, Spectrochimica Acta, 78, 160-167.

[38]. Asiri, A.M., Karabacak, M., Kurt, M., Alamry, K.A., 2011. Synthesis, molecular conformation, vibrational and electronic transition, isometric chemical shift, polarizability and hyperpolarizability analysis of 3-(4-Methoxyphenyl). Spectrochimica Acta, 82, 444-455.

[39]. Murray, J.S., Sen, K., 1996.Molecular Electrostatic Potentials: Concepts and Applications. Elsevier, Amsterdam, pp 122130.

[40]. Fleming, I., 1976. Frontier Orbitals and Organic Chemical Reactions. John Wiley \& Sons, New York, pp. 5-27.

[41]. Alcolea Palafox, M., 2000. Scaling factors for the prediction of vibrational spectra. I. Benzene molecule. Quantum Chemistry, 77, 661-684. 